\title{
Physical Education at Secondary School Level in Gujranwala,
}

\section{Pakistan}

\author{
Dr. Muhammad Sarwar (Corresponding author) \\ Department of Education, University of Sargodha, Pakistan \\ Tel: 92-321-860-0055 E-mail: drsarwar@ymail.com \\ Dr. Shafqat Hussain \\ Department of Education, GC University Faisalabad, Pakistan \\ Tel: 92-771-1441 E-mail: drhssn@yahoo.com \\ Tariq Mehmood \\ Education Department, Government of Punjab, Pakistan \\ Tel: 92-300-645-8958Ｅ-mail: drtariqgu@yahoo.com \\ Dr. Riffat-un-Nisa Awan \\ Department of Education, University of Sargodha, Pakistan \\ Tel: 92-300-600-9104 E-mail: riffarukh@gmail.com
}

\begin{abstract}
It is common phrase a sound mind is in a sound body. In addition, involvement in physical activity can positively affect grade scores of students in elementary schools. Physical education can aware the individuals to keep themselves healthy and active. Through physical activities a student can cure himself from different types of diseases. The present study discusses the results of a survey conducted in an eastern city (Gujranwala) of Pakistan near the border of India. The Gujranwala is an industrial city consisting of mainly factory workers. The data revealed that the physical education teachers of schools in Gujranwala (Pakistan) have positive attitude towards physical education with no significant gender differences. The main problems in the development of physical education are lack of funds, space, facilities and no interest of staff, students and parents.
\end{abstract}

Keywords: Physical education, Secondary school, Attitude towards physical education, Pakistan

\section{Introduction}

The human body is made to move but most of the inventions of present age tend to prevent the person to move. To combat the decreasing levels of physical activity in many young people, health professionals in are calling upon school physical education to equip students with the skills and knowledge necessary to become physically active for a lifetime (Krouscas, 1999). Many behaviors such as physical inactivity and poor dietary habits, which are risk factors for cardiovascular diseases, are established in childhood (Harris et al., 1997). A positive attitude towards physical education and physical facilities are required to promote physical education in schools. Therefore, schools at all levels should develop and encourage positive attitudes toward physical exercise, providing opportunities to learn physical skills and to perform physical activities (American Heart Association, 1992).

The attitude towards physical education is mainly determined by curriculum content, class atmosphere, teacher behavior, dressing out, and self-perception (Krouscas, 1999). There is no difference in students' attitude towards physical education in elementary and secondary schools (Tomik, 2008).

Participation in physical activities helps physically vigor and promotes clear thinking mentally, it is common phrase that a sound mind is in a sound body. In America school physical education has been promoted by as one of 
the most promising interventions in the nation's battle against physical inactivity, obesity and morbidities (President's Council on Physical Fitness and Sports, 2009).

Physical education programs in schools can benefits the students as Sallis (1997) concluded that a health related physical education curriculum can provide students with substantially more physical activity during physical education classes

After establishing the significance of physical education, now the question is whether it is at the cost of other academic performance or not. Parents and students usually think that the time students use in physical activity or physical education decreases the time used on academic activity and hence it reduces academic performance of students. Physical activity can positively affect grade scores of students in schools (International Society of Sport Psychology, 1992). Trudeau and Shephard (2008) found that allocating up to an additional hour per day of curricular time to physical activity programmes does not affect the academic performance of primary school students negatively, even though the time allocated to other subjects usually shows a corresponding reduction.

Zaman (1995) related that Quaid-i-Azam regarded the pursuit of physical education and sports as an integral part of the educational process, it made strong an individual physically, mentally and morally. This education supports in learning discipline and develop the habit of team work.

Physical education is necessary for healthy mind and healthy body. The status of physical education in Pakistan is not up to the mark. Unfortunately in Pakistan this subject is totally ignored, the physical education teachers in Pakistan are underprepared and not prepared at all. Physical education teachers in secondary schools are either matriculate (10 years regular study) and have one year diploma in physical education or retired army soldiers having no training in physical education. Whereas the situation even worse in private schools, where usually untrained teachers work as physical education teachers. This state of affairs leads to the narrow view of physical education, restricted to only games and playing.

Physical education needs to be promoted in Pakistan. There are two basic elements in the development of physical education: attitude towards physical education and physical facilities. A survey of the attitude towards physical education teachers and physical facilities is needed for proper planning and development of physical education facilities. This makes this study imperative. This study explored the attitude of physical education teachers towards physical education. Moreover, it also explores the gender and qualification differences in attitude towards physical education.

\section{Methodology}

The population of the study was the physical education teachers of all government secondary schools in Gujranwala district (Pakistan). It is an industrial city in the eastern Pakistan. The data from local education department show that there were total 179 government schools in the Gujranwala district including 80 female and 99 male schools. Again there are 191 posts of physical education teachers in the district, amongst which 85 are filled and 106 are lying vacant. Among 85 physical education teachers 12 were ex-army soldiers with no training in physical education, 24 matriculate (10 years of education) with one year diploma and 49 were FA (12 years of education) with one year diploma in physical education. This state of affairs leads to the narrow view of physical education, restricted to only games and playing. One of the researchers who himself was a head of school managed to collect data. He visited the schools personally briefed the respondents that the collected data will be kept secret and will not be used in such a way that identity of the individuals could be traced. The respondents of the study consisted of 52 physical education teachers of Gujranwala district.

An attitude towards physical education scale used by Chan and LO (1992) was used with changes. The questionnaire was consisted of 38 Likert type item along with open ended questions and questions on background information.

Keeping in view the limited English language ability of the respondents, it was decided to translate the questionnaire into Urdu (National language of Pakistan). Again there was a problem that most of the respondents understand the terminology only in English. So, finally bilingual questionnaire was used.

The attitude towards physical education was measured by asking the respondents to indicate the extent of agreement and disagreements with each item of the scale on a five point scale of responses (strongly disagree, disagree, uncertain, agree, and strongly agree). The points on a scale were rated as strongly disagree $=1$, disagree $=2$, uncertain $=3$, agree $=4$, and strongly agree $=5$ in case of positive item. This coding was revered in case of items ( 22 , 23 and 24 are negative items). The item (38 attitude items) in the scale have high internal consistency (Cronbach Alpha $=0.92$ ). The scale has maximum score 190 for most positive attitude and minimum 38 for most negative 
attitude and the midpoint score 114 for neutral attitude towards physical education and sports. T-test, analysis of variance and Chi Square were used to analyze the data via statistical package for social sciences.

\section{Findings and conclusions}

The physical education teachers have positive attitude towards physical education and sports $(\mathrm{t}=18.59, \mathrm{df}=51$, $\mathrm{p}<.000$ ). There is no difference in attitude towards physical education of male and female physical education teachers of government secondary schools $(\mathrm{t}=.241, \mathrm{df}=50, \mathrm{p}<.81)$. similarly, No difference was found in the attitude towards physical education of respondents with different qualifications $(\mathrm{f}=.945, \mathrm{df}=5,46, \mathrm{p}<.461)$. The respondents considered the following barriers in the promotions of physical education: no funds $(62 \%)$, No space $(50 \%)$, No facilities $(38 \%)$, No interest of physical education teachers $(25 \%)$, No interest of teaching staff(13\%), Community disinterest(12\%), No interest of head teachers $(10 \%)$, Parental disinterest $(10 \%)$, Untrained PE teachers( $8 \%$ ), Religious restrictions (6\%), No interest of students (2\%), and Govt. disinterest(2\%).

It was concluded that the attitude of school principals and teachers towards physical education were positive. It was also noted that the attitude were not affected by age, sex, or type of schools (private and government). Lack of funds, space, facilities coupled with no interest of physical education teachers were the main barriers in the development of physical education.

\section{References}

Arabaci, R. (2009). Attitudes toward physical education and class preferences of Turkish secondary and high school students. Elementary Education Online, 8(1), 2-8,

Ginsburg, K. R. (2007). The Importance of Play in Promoting Healthy Child Development and Maintaining Strong Parent-Child Bonds. Guidance for the Clinician in Rendering Pediatric Care, Vol. 119, No. 1, p1-10.

Hargreaves, J. (1994). Sporting females: critical issues in the history and sociology of women's sports. Routledge. New York.

Harris, K.J., Andrews, A.P., Richter, K.P., Lewis, R.K., Johnston, J.A., James, V., Henke, L., and Fawcett, S.B. (1997). Reducing elementary school children risk of academic diseases through school lunch modifications, Nutrition education, and physical activity interventions. Journal of Nutrition Education, 29(4), 195-202.

Henning, B., Stark, T. (2001). Gender equity in a physical education classroom: a look at achievement and engagement in a heterogeneous coeducation classroom. Unpublished master thesis. Saint Xavier University and IRI/Skylight. Illinois, Chicago.

Koca, C., Atencio, M., and Demirhan, G. (2009). The place and meaning of the field of PE in Turkish young people's lives: a study using Bourdieu's conceptual tools. Sport, Education and Society. Sport, Education and Society, Vol. 14, No. 1, February 2009, pp. 55-75.

Koca, C. Asci, F.H. and Demirhan, G. (2005). Attitudes toward physical education and class preferences of Turkish adolescents in terms of school gender composition. ADOLESCENCE, Vol. 40, No. 158, 365-375.

Krouscas, J. A. (1999). Middle school students' attitudes toward a physical education program. Unpublished $\mathrm{PhD}$ thesis. Virginia Polytechnic Institute and State University.

President's Council on Physical Fitness and Sports. (2009). School Physical Education as a Viable Change Agent to IncreaseYouth Physical Activity. Research Digest, 10(2) p.1-8

Reid,J.M. (1998). Gender equity in coeducational institutions: myth or reality. Unpublished masters thesis. Concordia University, school of graduate studies, Canada.

Sallis J. F.,McKenzie, L., Alcaraz, J.E, Kolody, B. Faucette, N.,and Hovell M.E. (1997). American Journal of Public health, 87(8), 1348-1334.

Scraton,S. (1992). Shaping up to womanhood: gender and girls' physical education. Open University press. Philadelphia.

Tomik, R. (2007). School Sports Clubs Members' Attitudes towards Physical Education and Sport. Journal of Human Kinetics, 17, 89-104.

Tomik, R. (2008). Adolescent Attitudes towards Sport Depending on School Level, Gender and School Sports Club Membership. Journal of Human Kinetics, 20 (section 3) 121-130.

Trudeau, F., and Shephard, R. J. (2008). Physical education, school physical activity, school sports and academic performance. International Journal of Behavioral Nutrition and Physical Activity, 5 (10): 1-12.

Wright,J. (1996). Mapping te discourses of physical education: articulating a female tradition. Journal of curriculum studies, 28(3), 331-351.

Zaman, S. M. (1995). Quaid-i-Azam and education. National institute of Historical and cultural Research. Islama bad, Pakistan. 132-133. 